\title{
The mechanobiological theory: a unifying hypothesis on the pathogenesis of moyamoya disease based on a systematic review
}

\author{
Bhanu Jayanand Sudhir, MCh, ${ }^{1}$ Arun Gowda Keelara, MS, ${ }^{1}$ Easwer Harihara Venkat, $\mathrm{MCh},{ }^{1}$ \\ Ken Kazumata, MD, PhD, ${ }^{2}$ and Ananthalakshmy Sundararaman, $\mathrm{PhD}^{3}$
}

1Department of Neurosurgery, Sree Chitra Tirunal Institute for Medical Sciences and Technology, Trivandrum, Kerala State, India; 2Department of Neurosurgery, Hokkaido University Graduate School of Medicine, Sapporo, Japan; and ' ${ }^{2}$ Department of Cardiovascular Diseases and Diabetes Biology, Rajiv Gandhi Centre for Biotechnology, Trivandrum, Kerala State, India

\begin{abstract}
OBJECTIVE Moyamoya angiopathy (MMA) affects the distal internal carotid artery and is designated as moyamoya disease (MMD) when predisposing conditions are absent, or moyamoya syndrome (MMS) when it occurs secondary to other causes. The authors aimed to investigate the reason for this anatomical site predilection of MMA. There is compelling evidence to suggest that MMA is a phenomenon that occurs due to stereotyped mechanobiological processes. Literature regarding MMD and MMS was systematically reviewed to decipher a common pattern relating to the development of MMA.
\end{abstract}

METHODS A systematic review was conducted to understand the pathogenesis of MMA in accordance with PRISMA guidelines. PubMed MEDLINE and Scopus were searched using "moyamoya" and "pathogenesis" as common keywords and specific keywords related to six identified key factors. Additionally, a literature search was performed for MMS using "moyamoya" and "pathogenesis" combined with reported associations. A progressive search of the literature was also performed using the keywords "matrix metalloprotease," "tissue inhibitor of matrix metalloprotease," "endothelial cell," "smooth muscle cell," "cytokines," "endothelin," and "transforming growth factor" to infer the missing links in molecular pathogenesis of MMA. Studies conforming to the inclusion criteria were reviewed.

RESULTS The literature search yielded 44 published articles on MMD by using keywords classified under the six key factors, namely arterial tortuosity, vascular angles, wall shear stress, molecular factors, blood rheology/viscosity, and blood vessel wall strength, and 477 published articles on MMS associations. Information obtained from 51 articles that matched the inclusion criteria and additional information derived from the progressive search mentioned above were used to connect the key factors to derive a network pattern of pathogenesis.

CONCLUSIONS Based on the available literature, the authors have proposed a unifying theory for the pathogenesis of MMA. The moyamoya phenomenon appears to be the culmination of an interplay of vascular anatomy, hemodynamics, rheology, blood vessel wall strength, and a plethora of intricately linked mechanobiological molecular mediators that ultimately results in the mechanical process of occlusion of the blood vessel, stimulating angiogenesis and collateral blood supply in an attempt to perfuse the compromised brain.

https://thejns.org/doi/abs/10.3171/2021.6.FOCUS21281

KEYWORDS moyamoya disease; matrix metalloprotease; endothelial cell; smooth muscle cell; RNF213; wall shear stress

ABBREVIATIONS BA = basilar artery; $\mathrm{CAV}=$ cavernous; $\mathrm{CFD}=$ computational fluid dynamics; $\mathrm{EC}=$ endothelial cell; $\mathrm{EGA}=$ estimated gestational age; $\mathrm{ERK}=$ extracellular signal-regulated kinase; ET-1 = endothelin-1; GLUT1 = glucose transporter 1; ICA = internal carotid artery; MAPK = mitogen-activated protein kinase; MMA = moyamoya angiopathy; $\mathrm{MMD}=$ moyamoya disease; $\mathrm{MMP}=$ matrix metalloproteinase; $\mathrm{MMS}=$ moyamoya syndrome; $\mathrm{NO}=$ nitric oxide; $\mathrm{PCA}=$ posterior cerebral artery; $\mathrm{PHACE}=$ posterior fossa malformations, infantile hemangiomas of the neck and face, arterial anomalies, cardiac abnormalities, and eye abnormalities; $R E C K=$ reversion-inducingcysteine-rich protein with kazal motifs; $R N F 213=$ ring finger protein $213 ; \mathrm{SCL}=$ supraclinoid; $\mathrm{SMC}=$ smooth muscle cell; $\mathrm{TGF}-\beta 1=$ transforming growth factor $\beta-1 ; \mathrm{TIMP}=$ tissue inhibitor of MMP; WSS = wall shear stress.

SUBMITTED April 30, 2021. ACCEPTED June 17, 2021.

INCLUDE WHEN CITING DOI: 10.3171/2021.6.FOCUS21281. 
TABLE 1. Search keywords and results for the six key factors

\begin{tabular}{|c|c|c|c|c|c|}
\hline Authors \& Year & Key Factor & Keywords* & PubMed & Scopus & Eligible Articles \\
\hline Kim et al., $2015^{5}$ & \multirow[t]{3}{*}{ Arterial tortuosity } & \multirow{3}{*}{$\begin{array}{l}\text { Vascular morphology, } \\
\text { ICA }\end{array}$} & \multirow[t]{3}{*}{10} & & \multirow[t]{3}{*}{3} \\
\hline Jamil et al., $2016^{6}$ & & & & & \\
\hline An et al., $2019^{7}$ & & & & & \\
\hline Silva Neto et al., $2012^{10}$ & \multirow[t]{2}{*}{ Vascular angles } & \multirow{2}{*}{$\begin{array}{l}\text { Vascular angles, vas- } \\
\text { cular morphometrics }\end{array}$} & \multirow[t]{2}{*}{2} & \multirow[t]{2}{*}{1} & \multirow[t]{2}{*}{2} \\
\hline Sudhir \& Kumar, $2018^{12}$ & & & & & \\
\hline Kim et al., $2015^{5}$ & \multirow[t]{4}{*}{ WSS } & \multirow[t]{4}{*}{ CFD, WSS } & \multirow[t]{4}{*}{6} & & \multirow[t]{4}{*}{4} \\
\hline Jamil et al., $2016^{6}$ & & & & & \\
\hline Sudhir \& Kumar, $2018^{12}$ & & & & & \\
\hline Lee et al., $2016^{17}$ & & & & & \\
\hline Sonobe et al., $2014^{9}$ & \multirow[t]{5}{*}{ Molecular factors } & \multirow{5}{*}{$\begin{array}{l}\text { MMP, TIMP, immuno- } \\
\text { histochemistry }\end{array}$} & \multirow[t]{5}{*}{22} & & \multirow[t]{5}{*}{5} \\
\hline Fujimura et al., $2009^{22}$ & & & & & \\
\hline Kang et al., $2010^{23}$ & & & & & \\
\hline Kang et al., $2006^{24}$ & & & & & \\
\hline Park et al., $2014^{25}$ & & & & & \\
\hline Malik et al., $2011^{27}$ & Blood rheology/viscosity & Rheology, viscosity & 1 & & 1 \\
\hline Jamil et al., $2016^{6}$ & Blood vessel wall strength & Vessel wall properties & 2 & & 1 \\
\hline & Total & & 43 & 1 & 12 (2 duplicates \& 1 triplicate) \\
\hline
\end{tabular}

" The common keywords used in all the searches were "moyamoya" and "pathogenesis."

A LTHOUGH 6 decades have elapsed since the initial description of moyamoya angiopathy (MMA), its pathogenesis remains enigmatic. Associations of MMA with various conditions ranging from infections, tumors, arteriovenous malformations, and radiation therapy to genetic syndromes have been reported and referred to as moyamoya syndrome (MMS). The idiopathic variant, moyamoya disease (MMD), has been increasingly attributed to genetic mutations, particularly ring finger protein 213 (RNF213). ${ }^{1}$ The common factor between MMD and MMS is the anatomical site of involvement, the distal internal carotid artery (ICA), including its bifurcation. This raises the possibility of a common terminal pathway in the pathogenesis of MMA.

A preliminary evaluation of the literature led us to believe that vascular homeostasis was balanced by six key factors: arterial tortuosity, vascular angles, wall shear stress (WSS), molecular factors, blood rheology/viscosity, and blood vessel wall strength. Based on the information obtained through our literature survey, we devised a hypothesis: tilting the balance between the six key factors enumerated above leads to the development of MMA. We also sought to answer a key question: "Why does MMA typically affect the distal internal carotid artery?" In the quest to answer this question and test the hypothesis, we embarked on a systematic review of the literature.

\section{Methods}

To this aim, in November 2020, a systematic review was conducted in accordance with PRISMA guidelines. ${ }^{2}$ PubMed MEDLINE (US National Library of Medicine at the NIH) and Scopus were searched using "moyamoya" and "pathogenesis" as common keywords and specific keywords for each of the key factors (Table 1). Addition- ally, a literature search was performed using "moyamoya" and "pathogenesis" combined with reported associations (Table 2). A progressive search of the literature was also performed using the keywords: "matrix metalloprotease," "tissue inhibitor of matrix metalloprotease," "endothelial cell," "smooth muscle cell," "cytokines," "endothelin," and "transforming growth factor." This was done to derive more information on the missing links in the pathogenesis of MMA. The inclusion criteria were articles relevant to the pathogenesis of MMA and molecular biological research in MMA. The exclusion criteria included research papers relating to outcomes of MMD, surgical technical papers, other systematic reviews, and duplicate articles.

\section{Results}

The literature search yielded 44 published articles on MMD and MMS using keywords classified under the six key factors. After exclusion of articles that did not match the inclusion criteria $(n=28)$, duplicates $(n=2)$, and triplicate $(n=1), 12$ articles were reviewed. The additional search for articles on MMA and its associations recovered 477 articles. Research papers that did not yield information on the pathogenesis of MMA $(n=433)$ and duplicates $(n=3)$ were excluded; 41 articles were included. Scrutiny of the results of the two searches revealed 2 duplicates. Thus, information obtained from 51 (12 [from search 1] +41 [from search 2]) -2 duplicates) articles was used to build the hypothesis. The PRISMA flowchart for the article search is shown in Fig. 1.

\section{Discussion}

Vascular modeling during embryogenesis and subsequent remodeling is a continuum governed by normal endothelium interacting with the smooth muscle cell (SMC) 
TABLE 2. Search results using the keywords of associations of MMS

\begin{tabular}{|c|c|c|c|c|}
\hline $\begin{array}{l}\text { Authors } \\
\& \text { Year }\end{array}$ & Keywords & $\begin{array}{l}\text { PubMed } \\
2010-2020\end{array}$ & $\begin{array}{l}\text { PubMed } \\
\text { 1990-2009 }\end{array}$ & $\begin{array}{l}\text { Eligible } \\
\text { Articles }\end{array}$ \\
\hline Liu et al., $2011^{1}$ & \multirow[t]{4}{*}{ RNF213 mutation } & \multirow[t]{4}{*}{61} & & \multirow[t]{4}{*}{4} \\
\hline An et al., $2019^{7}$ & & & & \\
\hline Kotani et al., $2015^{8}$ & & & & \\
\hline Sonobe et al., $2014^{9}$ & & & & \\
\hline $\mathrm{Fu}, 2017^{26}$ & \multirow[t]{2}{*}{ Graves' disease } & \multirow[t]{2}{*}{32} & & \multirow[t]{2}{*}{2} \\
\hline Malik et al., $2011^{27}$ & & & & \\
\hline Desai et al., $2006^{29}$ & \multirow[t]{3}{*}{ Radiation-induced moyamoya } & \multirow[t]{3}{*}{11} & & \multirow[t]{3}{*}{3} \\
\hline Reynolds et al., $2016^{30}$ & & & & \\
\hline \multirow[t]{2}{*}{ Almeida et al., $2019^{31}$} & & & & \\
\hline & Protein $\mathrm{C}$ deficiency & 0 & 9 & 0 \\
\hline Kato et al., $2009^{37}$ & Sickle cell disease & 89 & & 1 \\
\hline Chung et al., $2007^{46}$ & Marfan syndrome & 2 & & 1 \\
\hline Boutouyrie et al., $2004^{42}$ & Ehlers-Danlos syndrome & 2 & & 1 \\
\hline Lancman et al., $1991^{85}$ & Fibromuscular dysplasia & 16 & & 1 \\
\hline Norton et al., $1995^{55}$ & \multirow[t]{2}{*}{ Neurofibromatosis } & \multirow[t]{2}{*}{70} & & \multirow[t]{2}{*}{2} \\
\hline Friedman et al., $2002^{56}$ & & & & \\
\hline & Osteogenesis imperfecta & 0 & 1 & 0 \\
\hline Kainth et al., $2013^{47}$ & \multirow[t]{3}{*}{ Down syndrome } & \multirow[t]{3}{*}{53} & & \multirow[t]{3}{*}{3} \\
\hline Jea et al., $2005^{48}$ & & & & \\
\hline Karousou et al., $2013^{49}$ & & & & \\
\hline Shiihara et al., $2005^{59}$ & \multirow[t]{2}{*}{ Costello syndrome } & \multirow[t]{2}{*}{2} & & \multirow[t]{2}{*}{2} \\
\hline Hatamochi et al., $2000^{60}$ & & & & \\
\hline Hung et al., $2011^{62}$ & Noonan syndrome & 8 & & 1 \\
\hline Ishiguro et al., $2002^{63}$ & Cardiofaciocutaneous syndrome & 0 & 1 & 1 \\
\hline Pabst et al., $2021^{64}$ & Leguis syndrome & 1 & & 1 \\
\hline Woolfenden et al., 199965 & Alagille syndrome & 6 & & 1 \\
\hline Qaiser et al., $2009^{66}$ & Robinow syndrome & 0 & 1 & 1 \\
\hline Kılıç et al., $2012^{70}$ & $\begin{array}{l}\text { Microcephalic osteodysplastic primor- } \\
\text { dial dwarfism }\end{array}$ & 10 & & 1 \\
\hline Codd et al., $2009^{71}$ & Seckel syndrome & 2 & & 1 \\
\hline Shiihara et al., $2005^{59}$ & Schimke immunoosseous dysplasia & 1 & & 1 \\
\hline Miskinyte et al., $2011^{73}$ & \multirow[t]{2}{*}{ Xp28 (BRCC3) mutation } & \multirow[t]{2}{*}{4} & & \multirow[t]{2}{*}{2} \\
\hline Boudreau et al., $2007^{74}$ & & & & \\
\hline Fierini et al., $2015^{78}$ & \multirow[t]{2}{*}{ Sneddon syndrome } & 3 & & 2 \\
\hline Carhuapoma et al., $1999^{80}$ & & & & \\
\hline Carhuapoma et al., $1999^{80}$ & Systemic lupus erythematosus & 18 & & 1 \\
\hline Ramesh et al., $2010^{81}$ & Aicardi-Goutières syndrome & 5 & & 2 \\
\hline Crow \& Manel, $2015^{82}$ & & & & \\
\hline Hervé et al., $2014^{83}$ & GUCY1A3 mutation & 6 & & 1 \\
\hline Guo et al., $2009^{84}$ & ACTA2 mutation & 9 & & 1 \\
\hline Lancman et al., $1991^{85}$ & Turner syndrome & 6 & & 1 \\
\hline Tortora et al., $2017^{86}$ & PHACE syndrome & 12 & & 3 \\
\hline Greenberger \& Bischoff, $2013^{87}$ & & & & \\
\hline Kumagai et al., $2002^{88}$ & & & & \\
\hline Mikami et al., $2019^{75}$ & "Moyamoya" with infections & 36 & & 3 \\
\hline Meli et al., $2003^{76}$ & & & & \\
\hline Majeed et al., $2016^{77}$ & & & & \\
\hline & Total & 465 & 12 & 41 (3 duplicates) \\
\hline
\end{tabular}




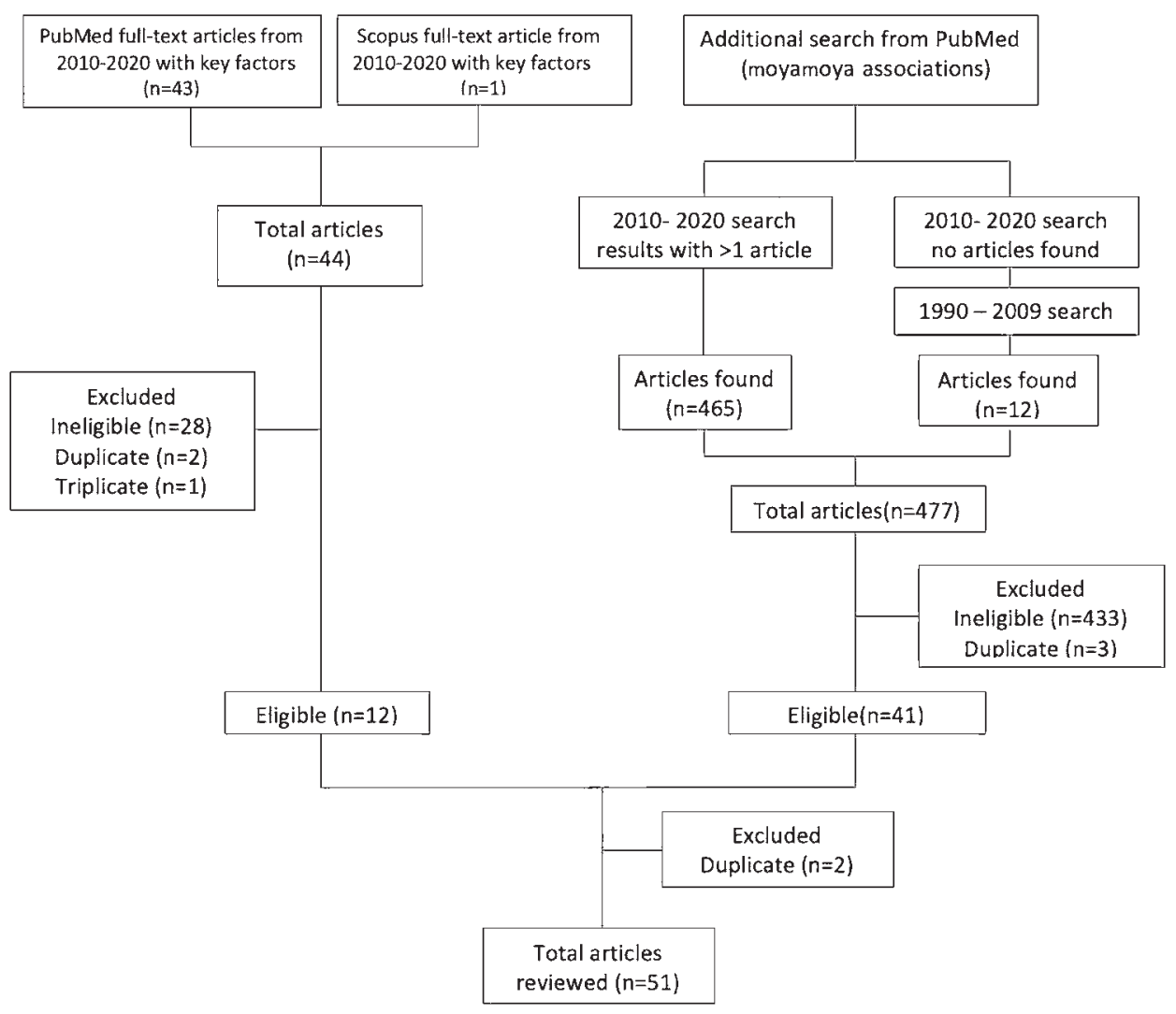

FIG. 1. PRISMA flowchart showing the search strategy and review process used to select articles for inclusion in this systematic review.
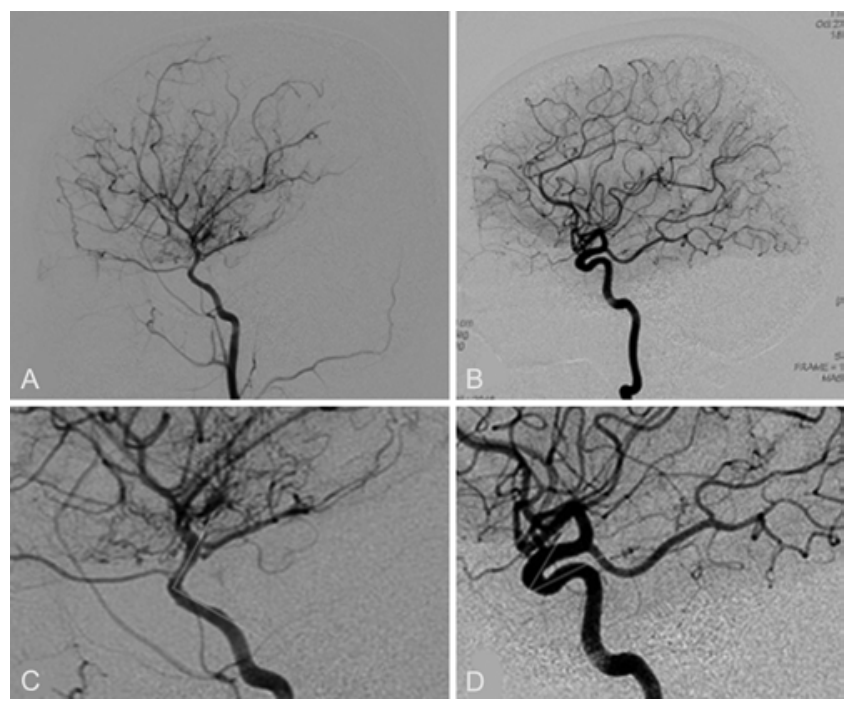

FIG. 2. A and B: Lateral angiograms obtained in a patient with MMA (A) and in another patient without MMA $(B)$ showing loss of tortuosity of the ICA. C and D: The CAV-SCL angle marked on lateral angiograms. The angle is greater in the patient with MMA (C) than in the patient without MMA (D). layer through molecular signal pathways. Additional players in this homeostasis include hemodynamic factors and blood vessel strength. Disruption of this delicate balance occurring at the distal ICA could be the cause of MMA. This discussion attempts to present literature supporting this hypothesis.

\section{Tortuosity of the ICA}

The ICA develops from the third branchial arch artery and distal part of the dorsal aorta (the estimated gestational age [EGA] is 28 days). ${ }^{3}$ As the embryo reaches an EGA of 44 to 48 days, with the descent of the heart into the thoracic cavity, the common carotid artery elongates to address the increasing distance between the brain and the heart. By an EGA of 51 days, the head-trunk angle progressively becomes less acute. ${ }^{4}$ The ICA takes a less tortuous and relatively straight course between its origin from the common carotid artery and the ICA bifurcation until the development of the lobes of the brain and the soft tissues of the neck on either side of the bone forming the skull base. In its final form, the ICA has predictable curves and tortuosity.

Observations of a loss of tortuosity of the ICA have led investigators to explore if a "straighter" course of the ICA to the brain could lead to the changes seen in MMA (Fig. 2). Kim et al. objectively measured the loss of tortuosity of the intracranial-extradural ICA. ${ }^{5}$ The tortuosity of the ICA in patients with MMD (18\%) was lower compared 
TABLE 3. Demographic and clinical profile of 15 patients with unilateral MMD

\begin{tabular}{|c|c|c|c|c|c|}
\hline Pt No. & Age (yrs) & Sex & Onset Symptom & Brain Lesion & Comorbidity \\
\hline 1 & 14 & M & TIA & None & \\
\hline 2 & 11 & $\mathrm{~F}$ & TIA & None & \\
\hline 3 & 23 & $\mathrm{~F}$ & Asymptomatic & Rt parietal white matter infarct & \\
\hline 4 & 14 & M & TIA & None & \\
\hline 5 & 49 & $\mathrm{~F}$ & Asymptomatic & Lt temporal infarction & Hypertension \\
\hline 6 & 21 & $\mathrm{~F}$ & TIA & None & \\
\hline 7 & 49 & M & Asymptomatic & None & \\
\hline 8 & 43 & $\mathrm{~F}$ & Asymptomatic & None & \\
\hline 9 & 41 & $\mathrm{~F}$ & Asymptomatic & None & \\
\hline 10 & 43 & M & Asymptomatic & Rt deep white matter infarcts & Hypertension, anxiety \\
\hline 11 & 7 & M & TIA & None & \\
\hline 12 & 52 & $\mathrm{~F}$ & TIA & None & \\
\hline 13 & 42 & M & Asymptomatic & None & \\
\hline 14 & 31 & M & TIA & None & \\
\hline 15 & 56 & M & Asymptomatic & Bilat deep white matter infarct & Diabetes mellitus, depression \\
\hline
\end{tabular}

$\mathrm{Pt}=$ patient; $\mathrm{TIA}=$ transient ischemic attack .

with the control group (37\%). Computational fluid dynamics (CFD)-based flow simulation revealed high WSS levels at the ICA bifurcation and proximal middle cerebral artery in models with lower tortuosity, albeit with a lower blood flow velocity in the MMD group. Similar observations of a lower tortuosity, especially that of the posterior bend of the carotid siphon, were reported by Jamil et al. ${ }^{6}$

RNF213 gene variant R4810.K in patients with MMD is associated with a loss of tortuosity of the ICA. ${ }^{7}$ Antisense mediated knockdown of $R N F 213$ results in a delay in straightening of the head-trunk angle in zebrafish embryos. RNF 213 is involved in the maturation of fast muscle cells and in neuromuscular regulation. ${ }^{8}$ Thus, we speculate that the delay in straightening of the craniocervical flexure could result in a desynchronization of development of craniocervical vasculature, causing the loss of tortuosity of the ICA. In the normal process of development of the ICA in relation to the head and neck, the length of the ICA would be synchronized to the development of the head and neck as well as the extension of the head on the neck in the embryo. Mutation of RNF213, through its influence on molecular pathways, matrix metalloproteinase (MMP) and tissue inhibitor of MMP (TIMP), could delay extension of the head on the neck in the embryo, resulting in stretching and loss of tortuosity of the ICA.?

\section{Vascular Angles}

Cavernous-Supraclinoid Angle of the ICA

A parameter that develops in similar lines as tortuosity of blood vessels is the angle between the cavernous (CAV) and supraclinoid (SCL) segments of the ICA. The CAV-SCL angle represents the angle between the fixed CAV segment and the relatively mobile SCL segment. The CAV-SCL angle is measured by drawing intersecting lines through center points of these segments. The carotid siphon anatomy has been studied in relation to the occur- rence of intracranial aneurysms, and the mean CAV-SCL angle has been reported to be $34.8^{\circ} .^{10,11} \mathrm{~A}$ higher CAVSCL angle was observed in patients with MMD compared with an age-matched control group (Fig. 2). ${ }^{12}$ CFD-based studies using four ICA models with increasing CAV-SCL angles revealed the occurrence of an area of high WSS in the vicinity of the ICA bifurcation in the model with the highest CAV-SCL angle. ${ }^{12}$ Thus, both a decrease in tortuosity and an increase in the CAV-SCL angle of the ICA result in higher WSS at the ICA bifurcation., 512

Unpublished data from a cohort of 15 patients with unilateral MMD at Hokkaido University between 2007 and 2017 confirmed the finding of a higher CAV-SCL angle in the affected hemisphere of the brain (Table 3). Longitudinal observational data also show wide variation in the CAV-SCL angle recorded at various time points during the follow-up of these patients (Table 4 and Fig. 3) (K. Kazumata, personal communication, October 27, 2017). The SCL ICA can thus be considered a "flail" segment relative to the CAV segment; in other words, the CAV-SCL angle is determined by the blood flow, behaving akin to an air dancer, rendered turgid by the air blown through it and collapsing when the airflow is reduced. This varying CAV-SCL angle implies that different areas of the SCL ICA are subject to changes in WSS over time. The changes in WSS and its effects on the endothelium are discussed in detail below.

\section{Basilar Artery-Posterior Cerebral Artery Angle}

A correlation has been identified between a smaller basilar artery (BA)-posterior cerebral artery (PCA) angle and progression of posterior circulation MMD. ${ }^{13}$ A low WSS occurring at BA bifurcation in 2D CFD studies has also been reported. Since both the BA and PCAs are cisternal arteries, the restraint-mobility factor considered in the CAV-SCL angle of the ICA may not be applicable to the PCA. We speculate that a higher angle between the BA 
TABLE 4. Observations of the measured CAV-SCL angle in the affected and nonaffected hemispheres of 15 patients with unilateral MMD

\begin{tabular}{|c|c|c|c|c|c|}
\hline Pt No. & $\begin{array}{c}\text { No. of Times } \\
\text { Observations Taken }\end{array}$ & $\begin{array}{l}\text { Mean Angle, Affected } \\
\text { Hemisphere }\left({ }^{\circ}\right)\end{array}$ & $\begin{array}{c}\text { SD, Affected } \\
\text { Hemisphere }\left({ }^{\circ}\right)\end{array}$ & $\begin{array}{c}\text { Mean Angle, Nonaffected } \\
\text { Hemisphere }\left({ }^{\circ}\right)\end{array}$ & $\begin{array}{l}\text { SD, Nonaffected } \\
\text { Hemisphere }\left({ }^{\circ}\right)\end{array}$ \\
\hline 1 & 8 & 54.12 & 8.6 & 19.5 & 2.6 \\
\hline 2 & 7 & 60.42 & 7.5 & 26.1 & 5.7 \\
\hline 3 & 5 & 78 & 4.9 & 44 & 3.5 \\
\hline 4 & 4 & 69 & 13.4 & 34 & 4.5 \\
\hline 5 & 3 & 62.6 & 7.37 & 50.3 & 4.5 \\
\hline 6 & 3 & 55.3 & 9 & 28.6 & 7.5 \\
\hline 7 & 4 & 50.75 & 7.6 & 24.75 & 3.3 \\
\hline 8 & 3 & 40.3 & 2.5 & 34 & 1 \\
\hline 9 & 1 & 52.89 & & 23.01 & \\
\hline 10 & 3 & 59 & 1.7 & 36.3 & 2.3 \\
\hline 11 & 4 & 47.5 & 3.04 & 24.5 & 4.6 \\
\hline 12 & 6 & 43.5 & 7.8 & 58 & 4.04 \\
\hline 13 & 8 & 73.8 & 2.9 & 46.2 & 3.9 \\
\hline 14 & 2 & 20 & 1.9 & 30.5 & 3.3 \\
\hline 15 & 5 & 74.6 & 5.18 & 36.2 & 5.6 \\
\hline
\end{tabular}

A higher CAV-SCL angle was observed in the affected hemisphere compared with the nonaffected hemisphere. Similar trends of changes in the CAV-SCL angle were observed in the nonaffected hemisphere also, but these changes were not as pronounced as those in the affected hemisphere.

and PCAs allows laminar blood flow in contrast to a lower angle leading to turbulence and recirculation zones in the vicinity of BA bifurcation.

\section{Wall Shear Stress}

Experimentally, high WSS levels at curves have been found to induce cultured endothelial cells (ECs) to produce MMP-9. ${ }^{14}$ High WSS is the driving force for blood vessels to progress to dolichoectasia, a process mediated by MMP-9, resulting in a weakened blood vessel wall. Subjecting the carotid artery of rabbits to alternating high and low WSS resulted in two distinct responses. A sustained high WSS resulted in elongation, tortuosity, and an increase in the blood vessel diameter (ectasia). This was achieved by smooth muscle and endothelial proliferation. The ECs tended to proliferate to accommodate the increased luminal surface area. Thus, the endothelial proliferation did not result in intimal thickening. During
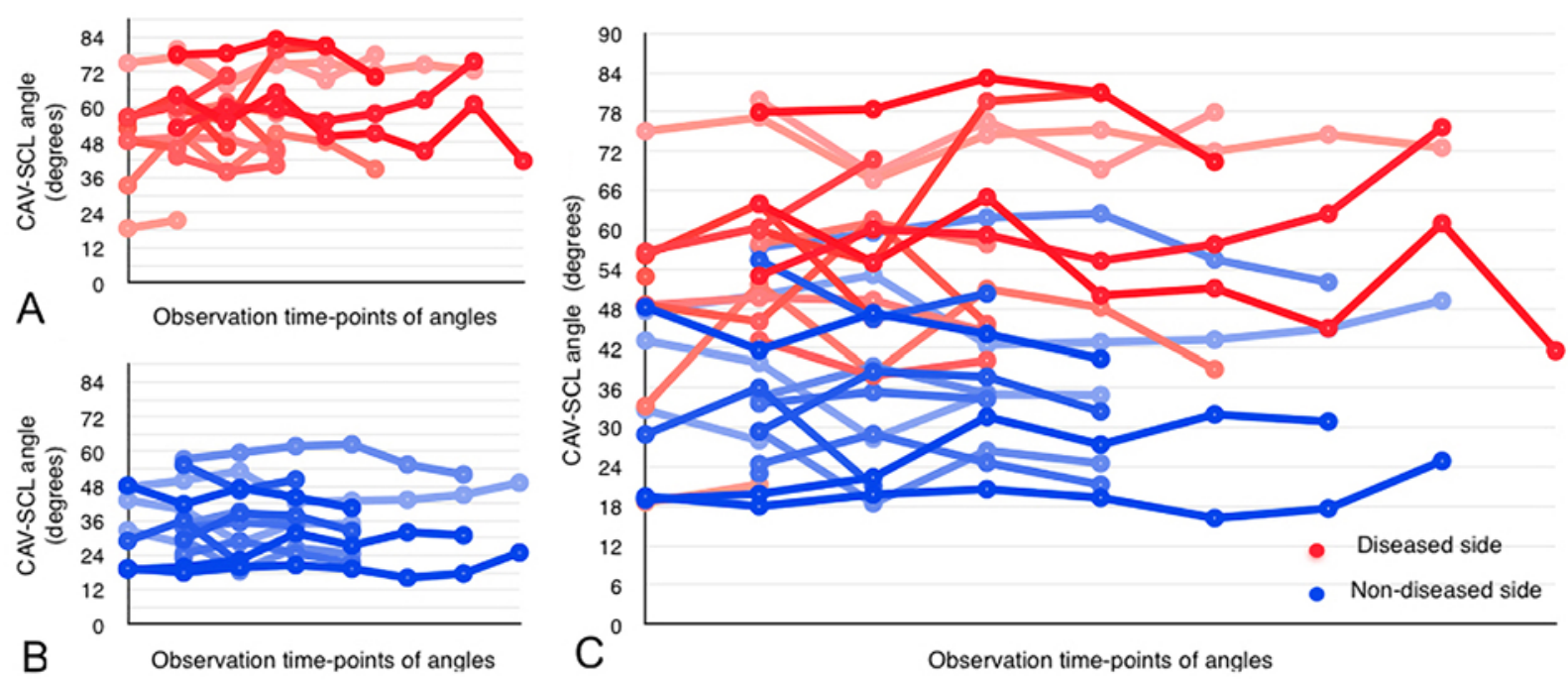

FIG. 3. Longitudinal time-line plots of the magnitude of CAV-SCL angle of a cohort of patients with unilateral MMD. The magnitude of the CAV-SCL angle is marked on the y-axis on a scale from $0^{\circ}$ to $90^{\circ}$ and the time points of observation on the $x$-axis. The scale for the $x$-axis has been avoided considering the nonuniformity of time points of observation between 2007 and 2017 . The points denote the time point of observation and the lines depict the trend of change of magnitude of the CAV-SCL angle. The affected hemisphere $(\mathbf{A})$, nonaffected hemisphere $(B)$, and a fused graph $(C)$ show a higher magnitude and greater variability of the CAV-SCL angle on the affected hemisphere compared with the nonaffected hemisphere. 
the low-flow phase, a relatively low WSS acted on the ectatic vessel. In an attempt to restore WSS to physiological levels, the blood vessel responded by shortening and constrictive remodeling, achieved by endothelial proliferation and resulting in thickening of the intima. Repeated cycles of high and low WSS resulted in progressive deposition of EC during the low WSS phases. ${ }^{15}$ Intimal thickening during low WSS exposure was also secondary to smooth muscle migration from the media to the intima and its proliferation, a process mediated by transforming growth factor $\beta-1$ (TGF $\beta-1) .{ }^{16}$

CFD-based studies using ICA models of reduced tortuosity and a higher CAV-SCL angle revealed areas of high

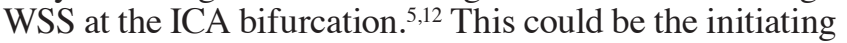
factor leading to intimal changes seen in MMA progressively inducing stenosis and compromising blood flow. An additional factor of a weak and floppy blood vessel would subject the SCL ICA to varying WSS, depending on its turgor as determined by the pressure of blood within the lumen. The SCL ICA suffers varying periods of high and low WSS, during each cardiac cycle as well as over a longer time frame, resulting in intimal thickening. Korean investigators have observed a correlation between the WSS value and progression of MMA. ${ }^{17}$

\section{Molecular Factors}

Variations in blood flow characteristics are "sensed" by the EC layer through mechanoreceptors. Responses to hemodynamic changes, both acute and chronic, are mediated by a network of biochemical pathways. ECs are subject to mechanical stimuli that include the blood pressure in the lumen, cell-cell junction tension, and WSS. Depending on its location and morphological characteristics, each blood vessel has a "physiological" WSS that maintains intimal homeostasis, preventing thrombosis, inflammation, and atherosclerosis. ${ }^{18}$ The EC surface proteins induce responses mediated by endothelin-1 (ET-1), nitric oxide (NO), and TGF $\beta$-1 resulting in proliferation, apoptosis, and realignment of ECs, countering situations that alter homeostasis.

WSS is the key driving force that regulates angiogenesis and the modeling of blood vessels during growth of the embryo. ${ }^{19}$ Physiological levels of WSS maintain a low (normal) level of MMP-2, stabilizing the blood vessel wall. This process is mediated by NO production, which acts through the p38/mitogen-activated protein kinase (MAPK) pathway, which downregulates the synthesis of MMP-2. ${ }^{20}$ Thus, alterations in WSS result in impaired production of NO, disrupting downstream pathways mediated through p38/MAPK. Such disruptions challenge the vascular modeling process both during embryonic development and during flow-dependent remodeling in children and adults.

In addition to the ECs, mechanical stimuli act on the SMCs in the tunica media across the internal elastic lamina. ${ }^{16}$ Intraluminal flow-induced pressure and shear stress induce angiotensin II, TGF $\beta$-1, platelet-derived growth factor (PDGF), and ET-1, which, through specific cell-surface receptors, act on SMCs and fibroblasts. In the case of PDGF and ET-1, downstream pathways in the SMCs and fibroblasts result in an upregulation of MMP-2 through PI3K-Akt pathways. Angiotensin II acts through the c-
Jun N-terminal kinase pathway and extracellular signalregulated kinase (ERK)/MAPK to upregulate MMP-2 and MMP-9, respectively. MMP-2 and MMP-9, both gelatinases, have a remarkable ability to degrade type IV collagen, a major component of the extracellular matrix..$^{21}$

The activity and levels of MMPs are regulated by TIMP and reversion-inducing-cysteine-rich protein with kazal motifs (RECK), a negative regulator for MMP-9. Under low WSS conditions, TGF $\beta-1$ is a crucial mediator of intimal thickening. ${ }^{16}$ TGF $\beta-1$ stimulates downstream pathways responsible for SMC migration and proliferation. The SMCs closer to the ECs are highly influenced and transgress the internal elastic lamina to reach the intima. SMC migration and proliferation are responsible for thickening of the intima. TGF $\beta$-1 acts through Smad (Smad7 and Smad4) proteins to raise the levels of TIMP. The balance between MMPs and inhibitors of metalloproteases (TIMP and RECK) maintains homeostasis in acute and chronic blood flow-related vessel wall changes. Alterations in the levels of MMP or TIMP result in disturbances of the structural integrity of the blood vessel by inducing vessel remodeling. Conversely, disturbances in blood flow could also tilt the balance of various mechanobiochemical pathways, resulting in altered levels of MMP and TIMP.

Experimental evidence of high levels of MMP-9 induced by high WSS at curves has been mentioned above in the section on WSS. ${ }^{14}$ High levels of MMP-9 have been found in the sera of patients with MMD. ${ }^{22}$ It is likely that the high MMP-9 levels could have contributed to the pathogenesis of the disease. High MMP-9 and low TIMP2 levels were also reported in plasma samples of patients with MMD. ${ }^{23}$ Familial MMD is associated with gene locations close to those locations encoding for TIMP-2 and TIMP-4. ${ }^{24}$ A TIMP deficit caused by mutation in the candidate genes could be responsible for uninhibited activity of MMP. Similar findings by Park et al. have reinforced the concept of a genetically induced imbalance between MMP and TIMP in MMD. ${ }^{25}$

An association between Graves' disease and MMA has been reported. ${ }^{26,27}$ Antithyroid antibodies have been implicated in the pathogenesis if MMA. ${ }^{27}$ High levels of MMP9 and TIMP are found in patients with Graves' disease, which correlated with high levels of antithyroid antibodies and ophthalmopathy. ${ }^{28}$ We speculate that these derangements in the MMP and TIMP balance could be responsible for MMA in Graves' disease.

There are multiple reports on the association of radiation-induced MMA. ${ }^{29-31}$ Irradiated ECs produced high levels of MMP-2 and MMP-9 compared with nonirradiated cell cultures. ${ }^{32}$ A possibility of oxidative stress and free radicals causing endothelial dysfunction and apoptosis has been reported, a phenomenon that has been reversed by retinoids and TIMP-1. ${ }^{33}$

The binding of protein $\mathrm{C}$ to its endothelial protein $\mathrm{C}$ receptor (EPCR) upregulates cytoprotective and antiinflammatory signaling pathways. ${ }^{34}$ High WSS promotes protein C-EPCR binding to maintain vascular wall homeostasis through antiinflammatory and cytoprotective pathways. ${ }^{35}$ Thus, a deficiency of protein $\mathrm{C}$, which is a reported association with MMA, results in deranged vessel wall mechanobiological responses to high WSS. ${ }^{36}$ 


\section{Blood Rheology and Viscosity}

In sickle cell disease, the adhesive properties of the erythrocytes and endothelium are altered. ${ }^{37}$ The deformed erythrocytes adhere to the endothelium, disrupting the normal pattern of axial concentration of erythrocytes. This results in a rise in blood viscosity. WSS is directly dependent on blood viscosity and is calculated as the product of wall shear rate and viscosity. ${ }^{38}$ Hemolysis results in exposure of naked oxyhemoglobin to NO, resulting in dioxygenation of NO, producing nitrates. ${ }^{39}$ Thus, NO, a key factor in vascular mechanobiology, is inactivated. This results in impaired responses of blood vessels to changes in flow dynamics. Baseline WSS measurements were found to be higher in patients with sickle cell disease. WSS-mediated vasodilatory response mediated by $\mathrm{NO}$ was impaired, and oxygen-dependent vasoconstriction and vascular remodeling in response to WSS have been found to be dysfunctional. ${ }^{40}$ Elevated levels of MMP-9 have been found in the plasma of patients with sickle cell disease compared with those without the disease. ${ }^{41}$

\section{Blood Vessel Wall Strength}

Although studies on blood vessel strength in MMD are lacking, the occurrence of MMA in connective tissue disorders such as Ehlers-Danlos syndrome, osteogenesis imperfecta, Marfan syndrome, fibromuscular dysplasia, and neurofibromatosis type 1 raises the possibility of an association with a weak blood vessel wall.

A study on the carotid arteries in vascular Ehlers-Danlos syndrome, caused by a mutation of gene encoding type III procollagen, revealed a lower wall-to-lumen ratio and intima-media thickness. ${ }^{42}$ Carotid artery WSS and distensibility were higher in patients with vascular Ehlers-Danlos syndrome than in controls.

Studies on mouse aorta collagen mutations have revealed that the presence of homotrimeric $\alpha 2$ (I) results in weakening of the blood vessel wall ${ }^{43}$ Homotrimeric $\alpha 2(\mathrm{I})$ is found in osteogenesis imperfecta and Ehlers-Danlos syndrome. The association of MMA in these conditions could be secondary to a weak blood vessel wall. ${ }^{44,45}$

The thoracic aorta in a mouse model of Marfan syndrome showed increased elasticity and an inability to contract in response to distention, a finding that correlated with high levels of MMP-2 and MMP-9. Fibrillin-1 is a downregulator of TGF $\beta$ - 1 . In Marfan syndrome, the loss of control over TGF $\beta-1$ leads to high levels of MMP-2 and MMP-9, resulting in destruction of the extracellular matrix and weakening of the blood vessel wall ${ }^{46}$

There are numerous reports of MMA occurring in patients with Down syndrome. ${ }^{47,48}$ The Down syndrome critical region 1 includes the genes encoding the collagen type VI. Trisomy 21 results in overexpression of COL6 $\alpha 2$, which is closely linked to expression of hyaluronan synthase 2, resulting in increased production of hyaluronan. ${ }^{49}$ Excessive deposition of hyaluronan creates a profibrotic environment in the tunica media and adventitia, increasing the stiffness of blood vessels. ${ }^{50}$ The resultant proinflammatory environment stimulates SMC migration and proliferation. Patients with Down syndrome are protected against the development of MMA due to an inherent low blood pressure acting on these stiff blood vessels. ${ }^{51-53}$ To this end, hypertension has been reported as a harbinger of MMA in Down syndrome. ${ }^{54}$

\section{The RASopathies}

Neurofibromin expression has been detected in mice and bovine EC cultures. ${ }^{55}$ Abnormal function of neurofibromin in neurofibromatosis type 1 possibly affects EC and SMC function in cerebral blood vessels. Two mechanisms for cerebral vasculopathy in neurofibromatosis type 1 have been proposed. Endothelial proliferation occurs secondary to breakdown of Ras signal pathways responsible for maintenance of the endothelium. Disruption of endothelial integrity, secondary to neurofibromin deficiency, could result in smooth muscle migration into the intima and proliferation of SMCs. ${ }^{56}$

In Costello syndrome, caused by mutations in the $H R A S$ gene, the $\mathrm{H}$-Ras protein (a GTPase involved in cell division, differentiation, and apoptosis) is in a triggered state, causing constant cell division. ${ }^{57}$ Impaired elastogenesis contributes to Costello syndrome..$^{58}$ Although a mutation of the elastin gene has not been identified in Costello syndrome, decreased expression of the elastin gene results in impaired elastogenesis, which is a hallmark found in most tissues in this syndrome..$^{59,60}$ This results in a weak blood vessel wall susceptible to hemodynamic stresses. We also speculate that in Costello syndrome a short neck could be the result of an asynchrony between the arteriogenesis and head-trunk angle development. A possible third contributing factor in this syndrome is the activation of the MAPK/ERK pathway in the ECs by the perpetually activated GTPase switch, resulting in increased levels of MMP-9. ${ }^{61}$

Noonan syndrome, characterized by developmental delay, a short and webbed neck, congenital cardiac defects, and skeletal abnormalities, results from a number of genetic mutations. The Ras/MAPK cell signaling pathway is hyperactivated. Noonan syndrome has rarely been associated with MMA..$^{61,62}$

Craniofacial abnormalities and a short neck could be secondary factors contributing to the pathogenesis of MMA in RASopathies including cardiofaciocutaneous syndrome and Leguis syndrome. .1,63,64 $^{6}$

\section{The Notch and Wnt Signal Pathways}

MMA has been reported to be associated with Alagille syndrome and Robinow syndrome. ${ }^{65,66}$ The Notch signaling pathway plays a crucial role in embryonic blood vessel development. ${ }^{67}$ The interplay of Notch and vascular endothelial growth factor signaling cascades regulate EC proliferation, survival, and angiogenesis. The Notch pathway is linked to the Wnt signaling pathway through the Notch-regulated ankyrin repeat protein (Nrarp) to coordinate stabilization of developing nascent vessels. ${ }^{68}$ Impaired expression of NOTCH3 in the SMCs of arteries results in enlargement of arteries with weak and thin smooth muscle layers. In Alagille syndrome, JAG1 mutation results in disruption of SMC differentiation. Mutations in JAG1,NOTCH2 (Alagille syndrome), and the Wnt pathway (Robinow syndrome) result in a weak blood vessel wall, precipitating MMA. 


\section{Miscellaneous Associations}

Chromatin Remodeling Osteodysplastic Syndromes

MMA has been reported as an association with microcephalic osteodysplastic primordial dwarfism (MOPDII), Seckel syndrome, and Schimke immunoosseous dysplasia. ${ }^{69-71}$ A common factor in these DNA repair-related syndromes is the occurrence of intrauterine growth retardation, short stature, and microcephaly. All of these syndromes fall under primordial dwarfism, where growth is restricted very early in embryonic development and continues to be so postnatally. Microcephaly is the result of impaired development of the brain from early development. A mismatch between brain development and cerebrovascular development is a likely triggering factor in the development of MMA in such cases. Another plausible mechanism is the secondary involvement of the MAPK/ ERK pathway. Primordial dwarfism is associated with mutations of the MAPK pathway resulting in impaired cell proliferation and differentiation.

\section{The DNA Repair Syndrome}

MMA is associated with $\mathrm{Xp} 28$ mutation, which results in loss of the $B R C C 3$ gene. ${ }^{72}$ Experiments in zebrafish revealed that $B R C C 3$ has a role in vascular development and angiogenesis. ${ }^{73}$ BRCC3 modulates the ERK pathway, which is responsible for control of cell survival, proliferation, and apoptosis. ${ }^{74}$ BRCC3 mutations could work through impaired ERK pathway signaling to precipitate MMA.

\section{Infections and Inflammation}

Associations of MMA with Mycobacterium tuberculosis, Haemophilus influenzae, Propionibacterium acnes, $\beta$-hemolytic group A Streptococcus, Streptococcus pneumoniae, Leptospira, Mycoplasma pneumoniae, human immunodeficiency virus, Epstein-Barr virus, and varicella zoster infection have been reported. ${ }^{75}$ The mechanism of MMA development due to infections has been proposed to be immune mediated. High levels of MMP-9 have been reported in the CSF and blood in tuberculous and pneumococcal meningitis, which correlated with the severity and progression of the disease. ${ }^{76,77}$ Varicella zoster, spreading from cervical sympathetic ganglia and optic nerves in herpes zoster ophthalmicus, may involve the cerebral arteries through a direct affection of the biochemical pathways in the ICAs. Similar pathophysiological mechanisms could be involved in MMA associated with autoimmune diseases, a process mediated by $R N F 213$ through proinflammatory cytokines, caveolin-1, ERK, and the Wnt signaling pathway in ECs and SMCs. ${ }^{68}$

A unique autoinflammatory condition that presents with MMA is Sneddon syndrome. ${ }^{78}$ Caused by a CECRI gene mutation, the clinical features include cerebral ischemic events and livedo racemosa. CECRI encodes for adenosine deaminase 2 (ADA2). However, ECs do not express $C E C R 1$, and $A D A 2$ is not detectable in human EC cultures. ${ }^{79}$ Deficiency of $A D A 2$ results in disruption of endothelial integrity in small arteries and impaired macrophage differentiation, resulting in a proinflammatory milieu in the vascular intima. Thus, an irreversible cycle of inflammation and vasculopathy occurs and results in
MMA. The phenotype resembles systemic lupus erythematosus with the coexistence of antiphospholipid antibodies, and is characterized by vascular stenosis, aneurysms, moyamoya, and stroke. ${ }^{80}$ The overlap with systemic lupus erythematosus suggests a common pathway to development of MMA in these two conditions.

Autoimmune-mediated inflammation leading to MMA is also described in Aicardi-Goutières syndrome. ${ }^{81}$ Among the six genotypes, only SAMHDI mutation is associated with MMA-like vasculopathy. Upregulation of type I interferon expression occurs in SAMHDI mutation through an accumulation of endogenous nucleic acid ligands. ${ }^{82}$

Hervé et al. reported the association between MMA and achalasia cardia in three families. ${ }^{83}$ Mutation of GUCY1A3, the gene that encodes the $\alpha 1$ subunit of soluble guanylate cyclase, which is a major receptor for NO, was found in the affected members. Shear stress-induced vascular remodeling involving ECs and SMCs is mediated by NO signaling pathways and ET-1. ${ }^{21}$ An impaired soluble guanylate cyclase-mediated response and the loss of inhibition on ET-1 of endothelium disrupts downstream pathways involving PI3K and MAPK/ERL, resulting in SMC proliferation and degradation of the extracellular matrix through uncontrolled MMP (MMP-2 and MMP-9) activity. Thus, the blood vessel wall loses its homeostatic balance between shear stress and vessel wall integrity.

Thoracic aortic aneurysms, dissection, and coronary artery disease in association with MMA have been identified to be caused by mutation of the ACTA2 gene. The hallmark of this disease is increased smooth muscle proliferation leading to vascular occlusions. The pathology affects the vasa vasorum of the thoracic aorta, coronary arteries, and SCL ICA. The polymerization of $\alpha$-actin modulates the phenotype of SMCs between a contractile cell and proliferative cell. ACTA2 mutation reduces the polymerization of $\alpha$-actin, thus stimulating proliferation of SMCs. However, the site specificity of the pathological process has been attributed to higher hemodynamic stresses undertaken by these arteries. To this end, in the background of ACTA2 mutation, high WSS may be the trigger for occlusive angiopathy. ${ }^{84}$

Similar pathogenetic mechanisms lead to the occurrence of MMA in Turner syndrome. ${ }^{85}$ The increased TGF $\beta-1$ found in this syndrome activates Smads, leading to increased levels of MMPs in the intima-media of the thoracic aorta in both Turner and Marfan syndromes; however, in Turner syndrome, multiple factors could be responsible for development of MMA, including low levels of protein $\mathrm{C}$, hypertension, estrogen deficiency, and autoimmunity.

MMA has been reported to occur in association with posterior fossa malformations, infantile hemangiomas of the neck and face, arterial anomalies, cardiac abnormalities, and eye abnormalities (PHACE) syndrome. ${ }^{86}$ ECs of infantile hemangiomas have been found to overexpress the glucose transporter 1 (GLUT1) causing increased transport of glucose into the ECs. The ECs are closely linked to pericytes through the Notch-Jagged1 pathway. ${ }^{87}$ The resulting glucotoxicity affects downstream pathways linked to GLUT1, causing DNA fragmentation and apoptosis of ECs. ${ }^{88}$ Endothelial NO production and GLUT1 expression 


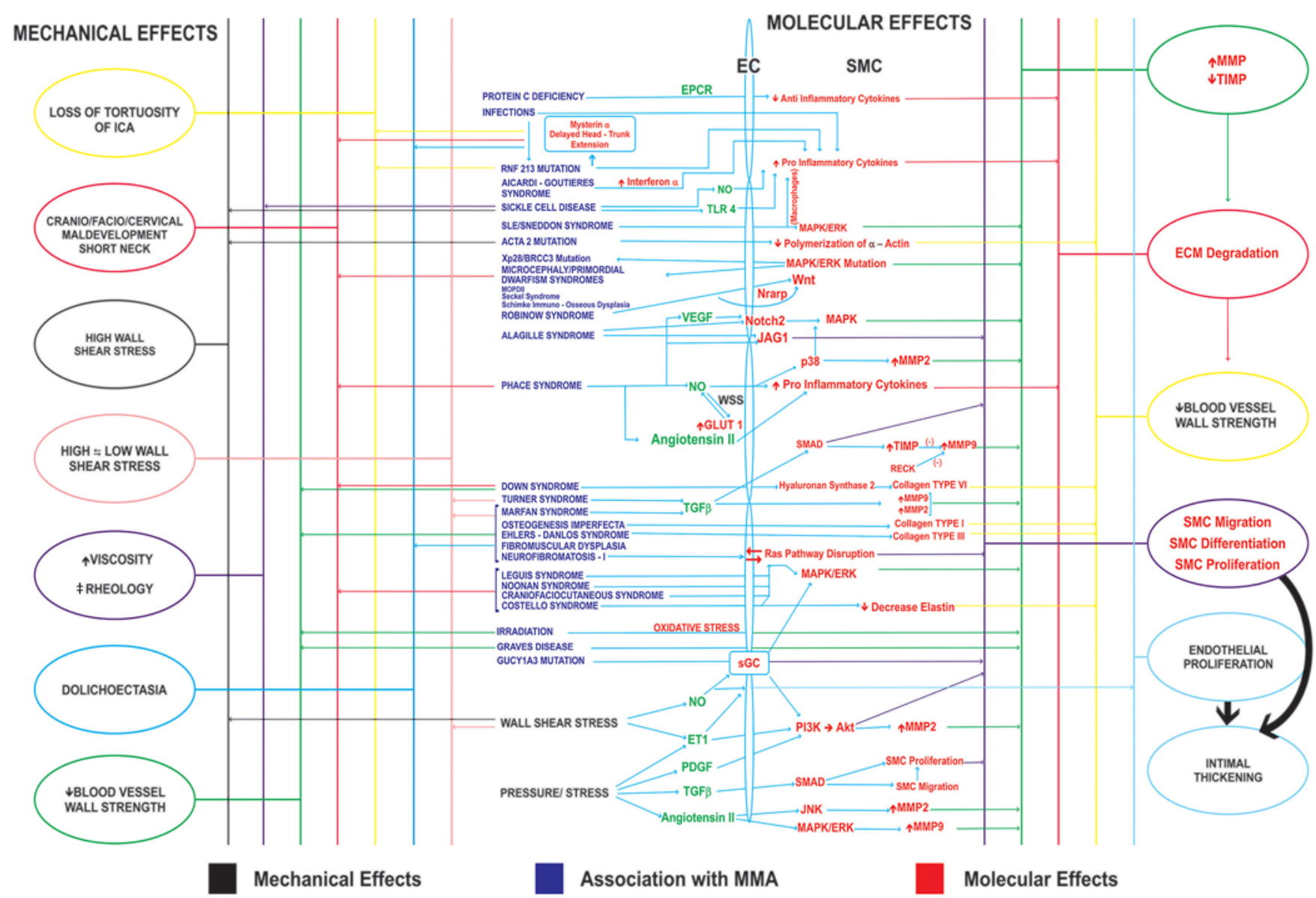

FIG. 4. The network algorithm representing the unified hypothesis of MMA. The links between morphological, mechanical, and molecular factors resulting in MMA are represented. ECPR = EC protein $\mathrm{C}$ receptor; MOPDII = microcephalic osteodysplastic primordial dwarfism type II; sGC = soluble guanylate cyclase; TLR $4=$ toll-like receptor 4; $\uparrow=$ increase in; $\downarrow=$ decrease in; $\ddagger=$ altered.

are balanced by WSS. ${ }^{89}$ Unregulated overexpression of GLUT1 disrupts this balance and WSS-induced NO production is upregulated. The damaged intima and high level of $\mathrm{NO}$ increases the levels of proinflammatory cytokines and p38-mediated SMC migration and proliferation, in addition to raising MMP levels. The link between GLUT1, the Notch regulator, and the hypoxia-inducible factor could as well explain the process of angiogenesis in MMA.90

\section{Toward a Unifying Hypothesis}

The complex interaction between the molecular mechanobiological pathways and their resultant mechanical changes which lead to endothelial and smooth muscle proliferation and result in intimal thickening and luminal occlusion is depicted in Fig. 4. Morphological determinants, including loss of tortuosity of the ICA, a lower BA-PCA angle, and a higher and variable CAV-SCL angle, subject the distal vasculature to higher hemodynamic stresses. The hemodynamic stress (WSS) acting on a weak blood vessel wall induces a series of downstream derangements in cytokines and biochemical factors that result in endothelial proliferation, SMC migration, and proliferation, resulting in intimal thickening and internal elastic lamina disintegration. Genetic diseases associated with MMS act by altering the blood vessel morphology, molecular pathways in the blood vessel wall, rheology of erythrocytes, and blood vessel wall strength. It appears that MMA is caused by a combination of factors acting at the distal ICA, resulting in EC and SMC proliferation and, therefore, occlusion. The very molecules mediating the process of occlusion, such as the MMPs and Notch pathway, could be responsible for angiogenesis resulting in collateral blood vessel formation, driven by hypoxia. ${ }^{68}$

\section{Conclusions}

This systematic review attempts to bring together the various mechanisms involved in the evolution of MMA that have been described with MMD and MMS under a single pathogenetic algorithm. The study is limited by our incomplete understanding of the interplay between biomechanical and molecular factors that regulate vessel wall remodeling; this is an emerging field of research. Our hypothesis does not account for incomplete penetrance of MMA in various clinical syndromes caused by underly- 
ing, complex genetic and environmental risk modifiers. Our hypothesis underscores the pathological cascade past a tipping point for disease development where we identify a common set of mechanobiological factors that cause vessel stenosis in both primary and secondary MMD.

The mechanobiological theory of MMA is proposed as follows: moyamoya is a phenomenon of development of collateral blood supply that evolves after occlusion of the distal ICA and/or BA in order to provide alternative channels for blood supply to the brain; the occlusion of the major blood vessels occurs due to a combination of mechanobiological factors that are genetic, developmental, hemodynamic, rheological, immunological, biochemical, and mechanical.

\section{References}

1. Liu W, Morito D, Takashima S, Mineharu Y, Kobayashi H, Hitomi T, et al. Identification of RNF213 as a susceptibility gene for moyamoya disease and its possible role in vascular development. PLoS One. 2011;6(7):e22542.

2. Moher D, Liberati A, Tetzlaff J, Altman DG; PRISMA Group. Preferred Reporting Items for Systematic Reviews and Meta-Analyses: the PRISMA statement. PLoS Med. 2009;6(7):e1000097.

3. Alexander MJ, Spetzler RF. Pediatric Neurovascular Disease: Surgical, Endovascular, and Medical Management. Thieme; 2011.

4. Menshawi K, Mohr JP, Gutierrez J. A functional perspective on the embryology and anatomy of the cerebral blood supply. J Stroke. 2015;17(2):144-158.

5. Kim T, Bang JS, Kwon OK, Hwang G, Kim JE, Kang HS, et al. Morphology and related hemodynamics of the internal carotid arteries of moyamoya patients. Acta Neurochir (Wien). 2015;157(5):755-761.

6. Jamil M, Tan GXY, Huq M, Kang H, Lee ZR, Tang PH, et al. Changes to the geometry and fluid mechanics of the carotid siphon in the pediatric moyamoya disease. Comput Methods Biomech Biomed Engin. 2016;19(16):1760-1771.

7. An S, Kim T, Oh CW, Bang JS, Lee SU, Heo J. Vascular tortuosity of the internal carotid artery is related to the RNF213 c.14429G > A variant in moyamoya disease. Sci Rep. 2019; 9(1):8614.

8. Kotani Y, Morito D, Yamazaki S, Ogino K, Kawakami K, Takashima $S$, et al. Neuromuscular regulation in zebrafish by a large AAA+ ATPase/ubiquitin ligase, mysterin/RNF213. Sci Rep. 2015;5(1):16161.

9. Sonobe S, Fujimura M, Niizuma K, Fujimura T, Furudate $\mathrm{S}$, Nishijima Y, et al. Increased vascular MMP-9 in mice lacking RNF213: moyamoya disease susceptibility gene. Neuroreport. 2014;25(18):1442-1446.

10. Silva Neto ÂR, Câmara RLB, Valença MM. Carotid siphon geometry and variants of the circle of Willis in the origin of carotid aneurysms. Arq Neuropsiquiatr. 2012;70(12):917-921.

11. Waihrich E, Clavel P, Mendes GAC, Iosif C, Moraes Kessler I, Mounayer C. Influence of carotid siphon anatomy on brain aneurysm presentation. AJNR Am J Neuroradiol. 2017;38(9): 1771-1775.

12. Sudhir BJ, Kumar KS. Moyamoya disease: using computational fluid dynamics to propose a novel "mechanical theory" of pathogenesis. In: 2018 International Conference on Intelligent Informatics and Biomedical Sciences (ICIIBMS). IEEE; 2018:72-77.

13. Lee JY, Kim SK, Cheon JE, Choi JW, Phi JH, Kim IO, et al. Posterior cerebral artery involvement in moyamoya disease: initial infarction and angle between PCA and basilar artery. Childs Nerv Syst. 2013;29(12):2263-2269.
14. Cooper S, Emmott A, McDonald KK, Campeau MA, Leask RL. Increased MMP activity in curved geometries disrupts the endothelial cell glycocalyx creating a proinflammatory environment. PLoS One. 2018;13(8):e0202526.

15. Sho E, Nanjo H, Sho M, Kobayashi M, Komatsu M, Kawamura K, et al. Arterial enlargement, tortuosity, and intimal thickening in response to sequential exposure to high and low wall shear stress. J Vasc Surg. 2004;39(3):601-612.

16. Sho M, Sho E, Singh TM, Komatsu M, Sugita A, Xu C, et al. Subnormal shear stress-induced intimal thickening requires medial smooth muscle cell proliferation and migration. Exp Mol Pathol. 2002;72(2):150-160.

17. Lee WJ, Jung KH, Lee KJ, Kim JM, Lee ST, Chu K, et al. Sonographic findings associated with stenosis progression and vascular complications in moyamoya disease. J Neurosurg. 2016;125(3):689-697.

18. Papaioannou TG, Stefanadis C. Vascular wall shear stress: basic principles and methods. Hellenic J Cardiol. 2005;46(1): 9-15.

19. Goktas S, Uslu FE, Kowalski WJ, Ermek E, Keller BB, Pekkan K. Time-series interactions of gene expression, vascular growth and hemodynamics during early embryonic arterial development. PLoS One. 2016;11(8):e0161611.

20. Milkiewicz M, Kelland C, Colgan S, Haas TL. Nitric oxide and 338 MAP kinase mediate shear stress-dependent inhibition of MMP-2 production in microvascular endothelial cells. J Cell Physiol. 2006;208(1):229-237.

21. Irons L, Humphrey JD. Cell signaling model for arterial mechanobiology. PLoS Comput Biol. 2020;16(8):e1008161.

22. Fujimura M, Watanabe M, Narisawa A, Shimizu H, Tominaga $T$. Increased expression of serum matrix metalloproteinase-9 in patients with moyamoya disease. Surg Neurol. 2009; 72(5):476-480.

23. Kang HS, Kim JH, Phi JH, Kim YY, Kim JE, Wang KC, et al. Plasma matrix metalloproteinases, cytokines and angiogenic factors in moyamoya disease. J Neurol Neurosurg Psychiatry. 2010;81(6):673-678.

24. Kang HS, Kim SK, Cho BK, Kim YY, Hwang YS, Wang KC. Single nucleotide polymorphisms of tissue inhibitor of metalloproteinase genes in familial moyamoya disease. Neurosurgery. 2006;58(6):1074-1080.

25. Park YS, Jeon YJ, Kim HS, Han IB, Oh SH, Kim DS, Kim NK. The GC + CC genotype at position -418 in TIMP-2 promoter and the $-1575 \mathrm{GA} /-1306 \mathrm{CC}$ genotype in MMP-2 is genetic predisposing factors for prevalence of moyamoya disease. BMC Neurol. 2014;14:180.

26. Fu MH. Concurrent moyamoya syndrome and Graves' disease: a case report. J Neurol Sci. 2017;381:413.

27. Malik S, Russman AN, Katramados AM, Silver B, Mitsias PD. Moyamoya syndrome associated with Graves' disease: a case report and review of the literature. J Stroke Cerebrovasc Dis. 2011;20(6):528-536.

28. Kapelko-Słowik K, Słowik M, Szaliński M, Dybko J, Wołowiec D, Prajs I, et al. Elevated serum concentrations of metalloproteinases (MMP-2, MMP-9) and their inhibitors (TIMP-1, TIMP-2) in patients with Graves' orbitopathy. $A d v$ Clin Exp Med. 2018;27(1):99-103.

29. Desai SS, Paulino AC, Mai WY, Teh BS. Radiation-induced moyamoya syndrome. Int J Radiat Oncol Biol Phys. 2006; 65(4):1222-1227.

30. Reynolds MR, Haydon DH, Caird J, Leonard JR. Radiationinduced moyamoya syndrome after proton beam therapy in the pediatric patient: a case series. Pediatr Neurosurg. 2016; 51(6):297-301.

31. Almeida P, Rocha A, Alves G, Parreira T, Silva ML, Cerejo A, et al. Moyamoya syndrome after radiation therapy: a clinical report. Eur J Case Rep Intern Med. 2019;6(12): 001337.

32. Nirmala C, Jasti SL, Sawaya R, Kyritsis AP, Konduri SD, 
Ali-Osman F, et al. Effects of radiation on the levels of MMP-2, MMP-9 and TIMP-1 during morphogenic glial-endothelial cell interactions. Int J Cancer. 2000;88(5):766-771.

33. Vorotnikova E, Tries M, Braunhut S. Retinoids and TIMP1 prevent radiation-induced apoptosis of capillary endothelial cells. Radiat Res. 2004;161(2):174-184.

34. Rezaie AR. Regulation of the protein $C$ anticoagulant and antiinflammatory pathways. Curr Med Chem. 2010;17(19): 2059-2069.

35. Dolan JM, Sim FJ, Meng H, Kolega J. Endothelial cells express a unique transcriptional profile under very high wall shear stress known to induce expansive arterial remodeling. Am J Physiol Cell Physiol. 2012;302(8):C1109-C1118.

36. Salih MA, Murshid WR, Al-Salman MM, Abdel-Gader AG, Al-Jarallah AA, Alorainy IA, et al. Moyamoya syndrome as a risk factor for stroke in Saudi children. Novel and usual associations. Saudi Med J. 2006;27(suppl 1):S69-S80.

37. Kato GJ, Hebbel RP, Steinberg MH, Gladwin MT. Vasculopathy in sickle cell disease: biology, pathophysiology, genetics, translational medicine, and new research directions. Am J Hematol. 2009;84(9):618-625.

38. Reneman RS, Hoeks APG. Wall shear stress as measured in vivo: consequences for the design of the arterial system. Med Biol Eng Comput. 2008;46(5):499-507.

39. Sundd P, Gladwin MT, Novelli EM. Pathophysiology of sickle cell disease. Annu Rev Pathol. 2019;14:263-292.

40. Belhassen L, Pelle G, Sediame S, Bachir D, Carville C, Bucherer C, et al. Endothelial dysfunction in patients with sickle cell disease is related to selective impairment of shear stress-mediated vasodilation. Blood. 2001;97(6):1584-1589.

41. Franco-Penteado CF, Hyslop S, Conran N, Saad STO, Costa FF. Increased levels and activities of matrix metalloproteinases in sickle cell disease. Blood. 2006;108(11):1220.

42. Boutouyrie P, Germain DP, Fiessinger JN, Laloux B, Perdu J, Laurent $\mathrm{S}$. Increased carotid wall stress in vascular EhlersDanlos syndrome. Circulation. 2004;109(12):1530-1535.

43. Vouyouka AG, Pfeiffer BJ, Liem TK, Taylor TA, Mudaliar J, Phillips CL. The role of type I collagen in aortic wall strength with a homotrimeric $[\alpha 1(\mathrm{I})]_{3}$ collagen mouse model J Vasc Surg. 2001;33(6):1263-1270.

44. Albayram S, Kizilkilic O, Yilmaz H, Tuysuz B, Kocer N, Islak C. Abnormalities in the cerebral arterial system in osteogenesis imperfecta. AJNR Am J Neuroradiol. 2003;24(4): 748-750.

45. Khandanpour N, Connolly DJA, Raghavan A, Griffiths PD, Hoggard N. Craniospinal abnormalities and neurologic complications of osteogenesis imperfecta: imaging overview. Radiographics. 2012;32(7):2101-2112.

46. Chung AWY, Au Yeung K, Sandor GGS, Judge DP, Dietz $\mathrm{HC}$, van Breemen C. Loss of elastic fiber integrity and reduction of vascular smooth muscle contraction resulting from the upregulated activities of matrix metalloproteinase- 2 and -9 in the thoracic aortic aneurysm in Marfan syndrome. Circ Res. 2007;101(5):512-522.

47. Kainth DS, Chaudhry SA, Kainth HS, Suri FK, Qureshi AI. Prevalence and characteristics of concurrent down syndrome in patients with moyamoya disease. Neurosurgery. 2013; 72(2):210-215.

48. Jea A, Smith ER, Robertson R, Scott RM. Moyamoya syndrome associated with Down syndrome: outcome after surgical revascularization. Pediatrics. 2005;116(5):e694-e701.

49. Karousou E, Stachtea X, Moretto P, Viola M, Vigetti D, D'Angelo ML, et al. New insights into the pathobiology of Down syndrome-hyaluronan synthase-2 overexpression is regulated by collagen VI $\alpha 2$ chain. FEBS J. 2013;280(10): 2418-2430.

50. Williams LM, McCann FE, Cabrita MA, Layton T, Cribbs A, Knezevic B, et al. Identifying collagen VI as a target of fibrotic diseases regulated by CREBBP/EP300. Proc Natl Acad Sci U S A. 2020;117(34):20753-20763.
51. Xu J, Shi GP. Vascular wall extracellular matrix proteins and vascular diseases. Biochim Biophys Acta. 2014;1842(11): 2106-2119.

52. Rodrigues AN, Coelho LC, Goncalves WL, Gouvea SA, Vasconcellos MJ, Cunha RS, Abreu GR. Stiffness of the large arteries in individuals with and without Down syndrome. Vasc Health Risk Manag. 2011;7:375-381.

53. Richards BW, Enver F. Blood pressure in Down's syndrome. J Ment Defic Res. 1979;23(2):123-135.

54. Santoro JD, Lee S, Mlynash M, Nguyen T, Lazzareschi DV, Kraler LD, et al. Blood pressure elevation and risk of moyamoya syndrome in patients with trisomy 21. Pediatrics. 2018; 142(4):e20180840.

55. Norton KK, Xu J, Gutmann DH. Expression of the neurofibromatosis I gene product, neurofibromin, in blood vessel endothelial cells and smooth muscle. Neurobiol Dis. 1995; 2(1):13-21.

56. Friedman JM, Arbiser J, Epstein JA, Gutmann DH, Huot SJ, Lin AE, et al. Cardiovascular disease in neurofibromatosis 1: report of the NF1 Cardiovascular Task Force. Genet Med. 2002;4(3):105-111.

57. HRAS gene. MedlinePlus Genetics. Accessed July 12, 2021. https://medlineplus.gov/genetics/gene/hras/

58. Krettek A, Sukhova GK, Libby P. Elastogenesis in human arterial disease: a role for macrophages in disordered elastin synthesis. Arterioscler Thromb Vasc Biol. 2003;23(4):582587.

59. Shiihara T, Kato M, Mitsuhashi Y, Hayasaka K. Costello syndrome showing moyamoya-like vasculopathy. Pediatr Neurol. 2005;32(5):361-363.

60. Hatamochi A, Nagayama H, Kuroda K, Shinkai H, Ishikiriyama S, Kobayashi M, Kobayashi K. Costello syndrome with decreased gene expression of elastin in cultured dermal fibroblasts. Dermatology. 2000;201(4):366-369.

61. Tidyman WE, Rauen KA. The RASopathies: developmental syndromes of Ras/MAPK pathway dysregulation. Curr Opin Genet Dev. 2009;19(3):230-236.

62. Hung PC, Wang HS, Wong AMC. Moyamoya syndrome in a child with Noonan syndrome. Pediatr Neurol. 2011;45(2): 129-131

63. Ishiguro Y, Kubota T, Takenaka J, Maruyama K, Okumura A, Negoro T, Watanabe K. Cardio-facio-cutaneous syndrome and moyamoya syndrome. Brain Dev. 2002;24(4):245-249.

64. Pabst L, Carroll J, Lo W, Truxal KV. Moyamoya syndrome in a child with Legius syndrome: Introducing a cerebral vasculopathy to the SPRED1 phenotype? Am J Med Genet A. 2021; 185(1):223-227.

65. Woolfenden AR, Albers GW, Steinberg GK, Hahn JS, Johnston DC, Farrell K. Moyamoya syndrome in children with Alagille syndrome: additional evidence of a vasculopathy. Pediatrics. 1999;103(2):505-508.

66. Qaiser R, Scott RM, Smith ER. Identification of an association between Robinow syndrome and moyamoya. Pediatr Neurosurg. 2009;45(1):69-72.

67. Murakami M. Signaling required for blood vessel maintenance: molecular basis and pathological manifestations. Int $J$ Vasc Med. 2012;2012:293641.

68. Phng LK, Potente M, Leslie JD, Babbage J, Nyqvist D, Lobov I, et al. Nrarp coordinates endothelial Notch and Wnt signaling to control vessel density in angiogenesis. Dev Cell. 2009; 16(1):70-82.

69. Clewing JM, Antalfy BC, Lücke T, Najafian B, Marwedel KM, Hori A, et al. Schimke immuno-osseous dysplasia: a clinicopathological correlation. J Med Genet. 2007;44(2):122-130.

70. Kılıç E, Utine E, Ünal S, Haliloğlu G, Oğuz KK, Cetin M, et al. Medical management of moyamoya disease and recurrent stroke in an infant with Majewski osteodysplastic primordial dwarfism type II (MOPD II). Eur J Pediatr. 2012;171(10): 1567-1571. 
71. Codd PJ, Scott RM, Smith ER. Seckel syndrome and moyamoya. J Neurosurg Pediatr. 2009;3(4):320-324.

72. Guey S, Tournier-Lasserve E, Hervé D, Kossorotoff M. Moyamoya disease and syndromes: from genetics to clinical management. Appl Clin Genet. 2015;8:49-68.

73. Miskinyte S, Butler MG, Hervé D, Sarret C, Nicolino M, Petralia JD, et al. Loss of BRCC3 deubiquitinating enzyme leads to abnormal angiogenesis and is associated with syndromic moyamoya. Am J Hum Genet. 2011;88(6):718-728.

74. Boudreau HE, Broustas CG, Gokhale PC, Kumar D, Mewani RR, Rone JD, et al. Expression of BRCC3, a novel cell cycle regulated molecule, is associated with increased phosphoERK and cell proliferation. Int J Mol Med. 2007;19(1):29-39.

75. Mikami T, Suzuki H, Komatsu K, Mikuni N. Influence of inflammatory disease on the pathophysiology of moyamoya disease and quasi-moyamoya disease. Neurol Med Chir (Tokyo). 2019;59(10):361-370.

76. Meli DN, Christen S, Leib SL. Matrix metalloproteinase-9 in pneumococcal meningitis: activation via an oxidative pathway. J Infect Dis. 2003;187(9):1411-1415.

77. Majeed S, Singh P, Sharma N, Sharma S. Title: role of matrix metalloproteinase -9 in progression of tuberculous meningitis: a pilot study in patients at different stages of the disease. BMC Infect Dis. 2016;16(1):722.

78. Fierini F, Barilaro A, Giambene B, Carlucci G, Grandi V, Maio V, Pantoni L. Moyamoya in a patient with Sneddon's syndrome. Clin Neurol Neurosurg. 2015;129:34-36.

79. Zhou Q, Yang D, Ombrello AK, Zavialov AV, Toro C, Zavialov $\mathrm{AV}$, et al. Early-onset stroke and vasculopathy associated with mutations in ADA2. N Engl J Med. 2014;370(10):911-920.

80. Carhuapoma JR, D'Olhaberriague L, Levine SR. Moyamoya syndrome associated with Sneddon's syndrome and antiphospholipid-protein antibodies. J Stroke Cerebrovasc Dis. 1999; 8(2):51-56.

81. Ramesh V, Bernardi B, Stafa A, Garone C, Franzoni E, Abinun $\mathrm{M}$, et al. Intracerebral large artery disease in AicardiGoutières syndrome implicates SAMHD1 in vascular homeostasis. Dev Med Child Neurol. 2010;52(8):725-732.

82. Crow YJ, Manel N. Aicardi-Goutières syndrome and the type I interferonopathies. Nat Rev Immunol. 2015;15(7):429-440.

83. Hervé D, Philippi A, Belbouab R, Zerah M, Chabrier S, Collardeau-Frachon S, et al. Loss of $\alpha 1 \beta 1$ soluble guanylate cyclase, the major nitric oxide receptor, leads to moyamoya and achalasia. Am J Hum Genet. 2014;94(3):385-394.

84. Guo DC, Papke CL, Tran-Fadulu V, Regalado ES, Avidan N, Johnson RJ, et al. Mutations in smooth muscle alpha-actin (ACTA2) cause coronary artery disease, stroke, and moyamoya disease, along with thoracic aortic disease. Am J Hum Genet. 2009;84(5):617-627.
85. Lancman M, Mesropian H, Serra P, Granillo R. Turner's syndrome, fibromuscular dysplasia, and stroke. Stroke. 1991; 22(2):269-271.

86. Tortora D, Severino M, Accogli A, Martinetti C, Vercellino N, Capra V, et al. Moyamoya vasculopathy in PHACE syndrome: six new cases and review of the literature. World Neurosurg. 2017;108:291-302.

87. Greenberger S, Bischoff J. Pathogenesis of infantile haemangioma. Br J Dermatol. 2013;169(1):12-19.

88. Kumagai AK, Jamali JA, Deo BK, Hosoya K, Terasaki T. Overexpression of GLUT1 and increased glucose transport leads to apoptosis in retinal endothelial cells. Invest Ophthalmol Vis Sci. 2002;43(13):1342.

89. Bharath LP, Cho JM, Park SK, Ruan T, Li Y, Mueller R, et al. Endothelial cell autophagy maintains shear stress-induced nitric oxide generation via glycolysis-dependent purinergic signaling to endothelial nitric oxide synthase. Arterioscler Thromb Vasc Biol. 2017;37(9):1646-1656.

90. Kim S, Lee M, Choi YK. The role of a neurovascular signaling pathway involving hypoxia-inducible factor and notch in the function of the central nervous system. Biomol Ther (Seoul). 2020;28(1):45-57.

\section{Disclosures}

The authors report no conflict of interest concerning the materials or methods used in this study or the findings specified in this paper.

\section{Author Contributions}

Conception and design: Sudhir, Venkat, Kazumata. Acquisition of data: Sudhir, Keelara, Kazumata. Analysis and interpretation of data: Sudhir, Keelara, Kazumata, Sundararaman. Drafting the article: Sudhir, Keelara, Sundararaman. Critically revising the article: Sundararaman. Reviewed submitted version of manuscript: Sudhir, Venkat, Kazumata. Approved the final version of the manuscript on behalf of all authors: Sudhir. Administrative/ technical/material support: Venkat, Kazumata. Study supervision: Venkat.

\section{Correspondence}

Bhanu Jayanand Sudhir: Sree Chitra Tirunal Institute for Medical Sciences and Technology, Trivandrum, Kerala State, India. bjs@ sctimst.ac.in. 